\title{
Las emisoras municipales en el País Vasco: Origen y Desarrollo
}

\author{
Dra. María Teresa Santos Díez \\ Profesora Titular Facultad CC.SS. y de la Comunicación UPV/EHU
}

\section{RESUMEN}

Las emisoras municipales en la Comunidad Autónoma Vasca han tenido escasa repercusión y aunque en un principio fueron muchos los Ayuntamientos interesados, pocos de ellos optaron por materializar el proyecto. Como medios municipales nacen con el fin de promover una estrecha relación entre el ciudadano y el propio Ayuntamiento, que posee entre otras misiones la aprobación de los presupuestos, plantilla, programación y asesoramiento. En el artículo se analizan estos medios es sus diversos aspectos.

\section{ABSTRACT}

Municipal radio stations in the Basque Autonomous Community have had scarce repercussion and although at first many town councils were interested, few of them decided to carry out their projects. As municipal media, they are born with the purpose of promoting a close relation between the citizen and the town council itself, having the latter, among other missions, the passing of the budgets, the list of staff, programming and advising. In the article these media are analysed in their diverse aspects.

Palabras claves: Comunidad Autónoma Vasca/Radios Municipales/Ayuntamiento/Legalización/ Medios locales/Concesión de Frecuencias.

Key words: Basque Autonomous Community/Municipal radio stations/Town council/Legalization/Local Media/Concesion of frecuencis.

\section{La radio municipal}

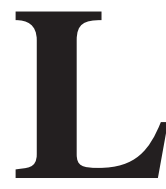

a Comunidad Autónoma encarna una realidad que se asienta sobre unos hechos históricos propios y peculiares. Desde abril de 1979, el Ayuntamiento es el órgano más representativo y cercano a los ciudadanos en cada localidad y como parte del Estado tienen derecho a crear sus propios medios de comunicación.

La emisora municipal necesariamente tendrá que encaminar sus esfuerzos a promover la comunicación a todos los niveles sin excluir a nadie debido a que ha sido reconocida por el Pleno del Ayuntamiento correspondiente. Sus objetivos no se centran en conseguir audiencias multitudinarias, ni competir con nadie sino, 
más bien pretenden ser de utilidad a la comunidad y, a través de ella, informar de los hechos más cercanos. Asimismo, servirá de herramienta de expresión educativa y creativa insertada en la realidad social. También existe la posibilidad de promocionar la cultura popular mediante el acceso de grupos locales, asociaciones y personas que quieran manifestar y expresar sus inquietudes culturales, por eso su cobertura será local.

Estos planteamientos iniciales suscitaron el interés de muchos Ayuntamientos, que solicitaron una concesión de frecuencia al Gobierno vasco, no obstante, en la mayoría de los casos no se materializaron los proyectos por diversas causas:

1) Una emisora supone un costo muy elevado para el municipio y los Ayuntamientos pequeños no pueden asumirlo.

2) No aporta un beneficio directo como sucede con otros servicios municipales.

3) Su dependencia del Pleno Municipal puede generar situaciones complicadas si responde a intereses exclusivistas.

4) La difícil situación política de la Autonomía.

5) Las restricciones que impone la propia legislación vigente.

Las emisoras municipales en un principio intentaron agruparse en una coordinadora con el fin de defender sus intereses y a la vez aunar criterios y promover iniciativas, pero ante el escaso empuje y falta de interés de la mayoría de los municipios fracasó el proyecto, de modo que ahora cada emisora resuelve su situación de manera independiente.

\section{Origen de las emisoras}

La primera experiencia tenía lugar en la localidad vizcaína de Amorebieta en abril de 1982, cuando un vecino presentó a la Corporación Municipal un estudio sobre el equipo técnico necesario para la instalación de la radio. La propuesta fue aprobada por el Ayuntamiento que además, facilitó un piso y el dinero necesario para que su apertura fuera una realidad. Zornotzako Udal Irratia el 2 de mayo de 1983 se convertía en la primera emisora municipal de la Comunidad Autónoma Vasca. Emitía Contaba una potencia de 50 vatios, que le permitía abarcar el municipio de Amorebieta-Etxano y alrededores. Disponía de un equipo técnico elemental, locutorio y control independientes, un juego de micrófonos, una mesa de mezclas, dos platos, una pletina y un emisor. La antena era una monopolo que estaba situado en el tejado del edificio.

Pretendía ${ }^{1}$ ofrecer una programación de ámbito local centrada en la información municipal ${ }^{2}$ y colaborar en la difusión del euskera. No obstante, Amorebie-

1 En un principio se retransmitían en directo los plenos Municipales, pero resultaban muy aburridos y se optó por dejar de hacerlo.

2 Zornotzako Udal Irratia iniciaba sus emisiones el 2 de mayo de 1983 precisamente con la presentación de los candidatos a las Elecciones Municipales que iban a celebrarse en fecha próxima. 
ta es una localidad pequeña, y en ella no suelen acontecer eventos relevantes, motivo por el cual desapareció el informativo diario, y se sustituyen por espacios deportivos, musicales, concursos, variedades y monográficos.

Después de algún tiempo comenzaron los primeros problemas con el Ayuntamiento ante la falta de un reconocimiento económico por el trabajo realizado, porque consideraba la emisora como un servicio que se ofrecía de forma voluntaria para efectuar unas prácticas. Esta respuesta vino suscitada fundamentalmente, por la escasa capacidad financiera de la Institución para asumir los gastos de personal. No obstante, accedió a comprar un fichero y unas mesas y de nuevo comenzó a emitir, pero con menor número de colaboradores. En enero de 1985, empezó un periodo de cambios continuos de programación y se decide únicamente emitir música durante tres horas al día, finalmente deja de emitir a primeros de 1989.

Otros Ayuntamientos como el de la localidad vizcaína de Lejona aceptaron ceder unos locales municipales para la ubicación de la radio aunque su finalidad fuera comercial a cambio de ceder un tiempo de programación para avisos y comunicados Institucionales como sucedió con $\mathrm{KV}-30^{3}$ que inició sus emisiones en diciembre de 1983; Radio 7 empieza a emitir desde Baracaldo ${ }^{4}$ en 1986 desde un piso municipal impulsada por un grupo de jóvenes; Unos años más tarde desde Getxo $^{5}$ surgía el proyecto de una radio Municipal y en enero de 1988 inicia sus emisiones. En 1989 lo hacía Gorliz Irratia impulsada por 15 jóvenes, que se organizan como una Asociación Cultural bajo el amparo del Ayuntamiento, pero con una finalidad comercial. Radio Top Abando surge en el año 1989 promovida por tres jóvenes, que en 1994 se constituyen como una Asociación Cultural con el apoyo del área de Cultura del Municipio de Abanto -Ciervana. En 1991 Durango Irratia empieza sus emisiones para toda la Mancomunidad con unos objetivos comerciales. Y más recientemente en 1998 desde Portugalete Hit Radio emite desde unas instalaciones cedidas por el Ayuntamiento de la localidad. En Guipúzcoa Oñate Irratia comenzó a emitir el 11 de mayo de 1991 promovida por su Ayuntamiento, y en el año 1994 lo hacía Arrasate Irratia desde Arrasate, una pequeña localidad que dispone de radio, televisión y además edita varias publicaciones periódicas.

Aunque todas estas emisoras de algún modo tienen una dependencia Institucional a lo largo de los años han experimentado procesos diferentes, y mientras unos Ayuntamientos han optado por legalizarlas otros en cambio permanecen en un periodo de estancamiento.

3 El Correo Español. KV-30 la emisora de Lejona. 5.4.1984, p.4.

4 Deia. Radio-7, la radio amiga de Baracaldo. 21.12.1987, p. 50

5 El Ayuntamiento de Getxo dispone de un Area de Comunicación que edita la publicación semanal GetxoBerri que centra sus contenidos en la información general de ámbito local. Además edita Gazteak, que es otra publicación gratuita destinada a los jóvenes. www. getxo.net 
Cuadro n. 1. Solicitud de emisoras. Año 1984

\begin{tabular}{lccc} 
& Alava & Vizcaya & Guipúzcoa \\
\hline Institucional & 6 & 62 & 22 \\
Asoc. Cultural & 3 & 23 & 18 \\
Privadas Comerciales & 8 & 13 & 4 \\
Total & 17 & 98 & 44 \\
Fuente: Gobierno vasco & & &
\end{tabular}

\section{La concesión de frecuencias}

El Departamento de Cultura del Gobierno vasco adjudicaba las primeras licencias de emisión en julio de 1987 teniendo en cuenta principalmente a empresas con alguna relación con el mundo de la información ${ }^{6}$, dejando al margen a las municipales y culturales ${ }^{7}$ que continuaban con sus emisiones de manera ilegal. Finalmente el 29 de diciembre de 1997 se adjudicaban de manera provisional la primeras licencias. En este reparto Guipúzcoa ha sido el territorio histórico más favorecido, mientras que Álava no obtenía ninguna.

\section{Cuadro n. 2. Concesión de emisoras por Territorios Históricos}

\begin{tabular}{lcc} 
& Primera & Segunda \\
\hline Vizcaya & 25,00 & 75,00 \\
Guipúzcoa & 75,00 & 25,00 \\
Álava & 0,00 & 0,00
\end{tabular}

El Gobierno Vasco adjudicaba de manera provisional las licencias de emisión basándose en el Decreto de 22 de marzo 1994 a las siguientes emisoras:

\section{1) Getxo Irratia}

Getxo Irratia comienza sus emisiones en enero de 1988 impulsada por el Ayuntamiento de la localidad vizcaína ante la necesidad de un mayor acercamiento de la Institución a los vecinos. Nace con el fin de fomentar la comunicación y

6 En Julio de 1987 el Gobierno Vasco adjudicaba las primeras concesiones de Emisoras de Frecuencia Modulada a empresas relacionadas con el mundo de la información y dos años más tarde, el 9 de agosto tenía lugar un segundo reparto de licencias.

7 El Decreto de 22 de marzo 1994, establecía el régimen de concesión del servicio público de radiodifusión sonora en Ondas Métricos con Modulación de Frecuencia para entidades municipales de la Comunidad Autónoma Vasca. 
participación ciudadana y a la vez promover una estrecha relación entre el ciudadano y la información del propio Ayuntamiento. Disponía de dos equipos emisores de 500 y 1.000 vatios cada uno, dos estudios con dos locutorios; un pequeño auditorio y sala de redacción. Emite en una frecuencia de 87.9 Mhz.

La emisora depende del Consejo de Control de los Medios de Comunicación, que a su vez, está constituido por todos los partidos políticos con representación municipal. Este organismo posee entre otras misiones la aprobación de los presupuestos, plantilla, programación y asesoramiento. Además, está sujeta a unos estatutos en los que se contempla la reglamentación de funciones, obligaciones objetivos, y derecho de réplica de la emisora. Desde el verano de 1994 la emisora no ha sufrido prácticamente ninguna variación debido básicamente a los desacuerdos municipales y los cambios que han tenido lugar en el Ayuntamiento.

En Getxo Irratia se tiende hacia una profesionalización de su personal ${ }^{8}$, aunque durante los primeros años la programación correspondiente a magazines y deportes se contrataba a una empresa. Con posterioridad comienza a emitir durante doce horas al día programación propia y el resto del tiempo conecta con Radio Euskadi ${ }^{9}$. La financiación se efectúa directamente mediante los fondos municipales.

\section{2) Oñate Irratia}

Esta emisora, que fue promovida por el propio Ayuntamiento de Oñate, inicia sus emisiones el 11 de mayo de 1991 con el objetivo de servir como medio de difusión de los acuerdos municipales y a la vez contribuir a la normalización del euskera. La radio depende de la Comisión de Cultura del Ayuntamiento donde hay un Consejo de Radio, que está integrado por los técnicos y políticos. Emite en una frecuencia de 107.4 Mhz. y una potencia de 150 vatios, dispone de un locutorio y control. No obstante, en los últimos tiempos han digitalizado la emisora, hecho que les permite emitir durante más horas. Comenzó a funcionar con una persona contratada por el Ayuntamiento que realizaba la dirección y coordinación de las tareas propias del medio y otra que se encargaba de la dirección de la publicidad, además de diez colaboradores. Con posterioridad se incrementa la plantilla y contratan dos periodistas que junto con doce colaboradores elaboran la programación propia. Su financiación corresponde al Ayuntamiento, aunque también tiene algo de publicidad. Oñate Irratia ${ }^{10}$ alterna programación propia con Euskadi Irratia.

8 En un primer momento los programas los realizaban estudiantes y personas interesadas en la radio. En el año 2000 trabajaban cuatro periodistas en plantilla y tres técnicos durante la semana, mientras que en fines de semana hay un equipo de dos periodistas y un técnico.

9 Radio Euskadi forma parte del Ente Vasco Euskal Irrati Telebista, que inicia su andadura el 23 de noviembre de 1982.

10 Euskadi Irratia aunque cubre toda la autonomía emite desde San Sebastián íntegramente en euskera. 


\section{3) Arrasate Irratia}

Arrasate Irratia empieza a emitir en 1994 promovida por la organización AEDE con el fin de fomentar el uso del euskera. Esta asociación la integran diversos medios de información que a su vez constituían ARKO (Arrasate Komunikabidea) que incluye Arrasate-Press, que edita un semanario que recoge las noticias de Mondragón y su zona de influencia además de Arrasate TV y Arrasate Irratia. Una vez legalizada, continúa dependiendo del Ayuntamiento, hasta mayo del 2002 que pasa a ser gestionada por ARKO directamente, y además cambia de locales.

Emite en una frecuencia de $107.7 \mathrm{MHz}$ y una potencia de $150 \mathrm{MHz}$ y dispone de un locutorio y dos controles. Durante los primeros años su financiación la realiza el Ayuntamiento, pero al cambiar su situación comienza a emitir publicidad. Tiene una plantilla de dos periodistas para la radio, aunque también participan otros seis que trabajan en Arrasate TV y Arrasate Pres y unos 50 colaboradores. A partir de septiembre del 2000 deja de conectar con Euskadi Irratia y la digitalización de la emisora les permite emitir las 24 horas del día, aunque sólo seis horas al día en directo ${ }^{11}$.

\section{Nuevas solicitudes}

En septiembre de 1998 los Ayuntamientos de Gorliz, Durango y Villabona presentan al Gobierno vasco un informe para la reserva de sus frecuencias. Ante el silencio administrativo Gorliz y Durango Irratia continúan con sus emisiones hasta que se aprueben los proyectos técnicos o, por el contrario, los rechacen.

\section{1) Gorliz Irratia}

Gorliz Irratia inicia sus emisiones de manera experimental en diciembre de 1989 impulsada por 15 jóvenes. Después de unos meses de emisiones intermitentes comenzó a emitir de manera continua en septiembre de 1990 desde una Ikastola de la localidad vizcaína de Gorliz con los siguientes objetivos:

1) Ser un medio de expresión para el pueblo.

2) Promocionar el euskera.

3) Permitir a los estudiantes de periodismo realizar prácticas, motivo por el cual se constituye como una Asociación Cultural.

Después de emitir durante cinco años se decide que sea municipal y el Ayuntamiento asume los gastos que ocasiona el alquiler de los locales, la luz y teléfono. En un principio emitía en una frecuencia de $107.2 \mathrm{MHz}$, pero con posterioridad pasó a ocupar la frecuencia 107.8 MHZ y amplía su potencia hasta 1 kilovatio con el fin de alcanzar una mayor cobertura y pasa a denominarse

11 La programación de elaboración propia consiste básicamente en informativos de ámbito local y Magazine que incluye agenda, titulares, entrevistas, etc. 
Gorliz Irratia- Kosta Uribe Irratia. Para su financiación recurren a la publicidad, pero como resulta insuficiente realizan otras actividades complementarias como pueden ser poner música en las fiestas, instalación de txoznas, etc., que les aportan unos beneficios que oscilan entre un 1.500 .000 pesetas y los 2.000 .000 de pesetas. Emiten 12 horas al día en directo, el resto del tiempo de programación es música grabada.

El Ayuntamiento es el responsable de la emisora, mientras que la gestión la realiza la Asociación Cultural que en un principio fue la promotora de la radio. Gorliz Irratia dispone de 4 periodistas, 1 comercial y 15 colaboradores para realizar una programación de 24 horas.

\section{2) Durango Irratia}

En junio de 1991 inicia sus emisiones desde la localidad vizcaína de Durango para toda la Mancomunidad. Su objetivo principal consiste en ofrecer un servicio al ciudadano, informándole de los acontecimientos que se generan en la comarca tanto a nivel institucional como de calle.

Emite en una frecuencia de 107.8 MH. y tiene una potencia de 100 vatios y cuenta con dos estudios para programas y otro para grabaciones de informativos, y con posterioridad pasa a digitalizar la emisora. Cuando el Ayuntamiento de Durango decide solicitar una frecuencia al Gobierno vasco pasa a ser gestionada de manera indirecta mediante una subcontratación a la empresa Akon, que tendrá que encargarse de la dirección, el personal, publicidad y programación. Durante los primeros años emitía durante tres horas al día una programación que incluía espacios informativos, magazines, musicales y deportes, pero con posterioridad pasa a estructurarla de otro modo y emite 24 horas.

\section{Características}

Las emisoras municipales aunque son muy escasas en la Comunidad Autónoma presentan las siguientes características:

\section{1) Personal}

Una de las grandes dificultades con que se encuentran las emisoras municipales para su desarrollo son los elevados costes que supone asumir los gastos de personal que requiere el servicio. Es indudable que si el Ayuntamiento no contempla en sus presupuestos a estos profesionales, la emisora se ve condena a una constante precariedad. Situación que se resuelve de diversos modos:

1) Ayuntamientos que asumen todos los gastos y la situación laboral de los trabajadores es similar al resto de empleados municipales, como sucede por ejemplo en el Ayuntamiento de Getxo, que dispone de una plantilla de seis periodistas y tres técnicos. De igual modo, Oñate Irratia cuenta con dos periodistas para cubrir las dos horas y media de programación 
propia y 12 colaboradores. El Ayuntamiento de Arrasate tiene una emisora de radio, televisión y una revista. Cuenta con ocho periodistas de los cuales dos están asignados de manera permanente a la radio, aunque no es un obstáculo para la colaboración entre los distintos medios, igual que los 50 colaboradores y becarios que integran el personal.

2) En otros casos el Ayuntamiento cede unos locales y acepta pagar los gastos mínimos como puede ser luz y teléfono, mientras que el personal no depende del Ayuntamiento como en Gorliz Irratia.

3) La gestión indirecta es la opción adoptada por el Ayuntamiento de Durango, de modo que los cuatro periodistas que trabajan en el medio dependen de la empresa que gestiona el medio, igual que Arrasate Irratia en su segunda etapa.

\section{Cuadro n.3. Personal}

\begin{tabular}{lcc}
1998 & Periodistas & Colaboradores \\
\hline Getxo & 4 & 0 \\
Oñate & 1 & 10 \\
Arrasate & 2 & 50 \\
Durango & 4 & 10 \\
Gorliz & 1 & 40
\end{tabular}

\section{Cuadro n.4. Personal}

\begin{tabular}{lcc}
2002 & Periodistas & Colaboradores \\
\hline Getxo & 6 & 0 \\
Oñate & 2 & 12 \\
Arrasate & 2 & 50 \\
Durango & 6 & 6 \\
Gorliz & 4 & 15
\end{tabular}

\section{2) Gestión}

Las emisoras, aunque tienen dependencia municipal, en la mayoría de los casos los Ayuntamientos ante la incapacidad de asumir los gastos que ocasiona recurren a gestionarlas por deferentes vías:

1) Gestión directa, de modo que su vinculación con la Institución se realiza mediante diversas fórmulas. Así, Getxo Irratia depende del Consejo de 
Control de los Medios de Comunicación que está constituido por los partidos políticos con representación municipal. Oñate Irratia está supeditada a la Comisión de Cultura, donde hay un consejo de radio que lo integran representantes de la emisora y de los partidos políticos.

2) En la gestión indirecta los Ayuntamientos delegan a otra entidad el medio, como sucede con Durango Irratia, donde la Institución concede una subvención y una empresa se encarga de todo lo referente a la radio, y Gorliz Irratia que es gestionada por una Asociación Cultura. En ambos casos recurren a la publicidad comercial con el fin de obtener beneficios.

\section{Cuadro n. 5. Tipo de Gestión}

\begin{tabular}{llc} 
& $\mathbf{1 9 9 8}$ & $\mathbf{2 0 0 2}$ \\
\hline Getxo & Ayuntamiento & Ayuntamiento \\
Oñate & Ayuntamiento & Ayuntamiento \\
Arrasate & Ayuntamiento & ARKO \\
Durango & AKON & AKON \\
Gorliz & Asoc. Cultural & Asoc. Cultural
\end{tabular}

\section{3) Frecuencia de emisión}

Las emisoras municipales en Vizcaya utilizan una frecuencia comprendida entre el 87.9 y el 107.8, mientras que en Guipúzcoa ocupan la banda entre 107.7 y $107.8 \mathrm{Mhz}$.

\section{Cuadro n.6. Frecuencia de emisión}

\begin{tabular}{lrr} 
& $\mathbf{1 9 9 8}$ & $\mathbf{2 0 0 2}$ \\
\hline Getxo & 87.9 & 87.9 \\
Oñate & 107.4 & 107.4 \\
Arrasate & 107.7 & 107.7 \\
Durango & 107.8 & 107.8 \\
Gorliz & 107.2 & 107.8
\end{tabular}

\section{4) Potencia}

Según el Decreto del Gobierno Vasco necesariamente estas emisoras deben de tener cobertura local. No obstante, este requisito es un grave inconveniente para 
la gestión publicitaria. De modo, que tienden a incrementar su cobertura dentro de un clima de tolerancia, mientras no produzcan interferencias con el fin de aumentar sus oyentes y su mercado publicitario. Su potencia, que en 1998 no superaba los 500 vatios en el año 2002 oscila entre los 150 vatios en Oñate y Arrasate hasta un kilovatio en Gorliz y Durango.

\section{Cuadro n.7. Potencia de emisión}

\begin{tabular}{lrr} 
& $\mathbf{1 9 9 8}$ & $\mathbf{2 0 0 2}$ \\
\hline Getxo & 500 & 1000 \\
Oñate & 150 & 150 \\
Arrasate & 150 & 150 \\
Durango & 100 & 1000 \\
Gorliz & 500 & 1000
\end{tabular}

\section{5) La Publicidad}

Getxo Irratia es la única emisora en la que el Ayuntamiento asume todos los gastos, de modo que no necesita recurrir a la publicidad comercial para obtener una financiación. En cambio, el resto de emisoras dispone de un departamento comercial que se encarga de gestionar todo lo relacionado con la publicidad, que cada vez se reduce más ante el incremento de medios locales que compiten por un mismo mercado. En 1998 los precios orientativos de una cuña de 20 segundos oscilaba entre 1,80 euros en Gorliz Irratia y 4,80 en Oñate Irratia, precios que se incrementan en el 2002 hasta los 6 euros en Arrasate Irratia.

Cuadro n.8. Precio de la publicidad cuñas de 20"

\begin{tabular}{lrr} 
& $\mathbf{1 9 9 8}$ & $\mathbf{2 0 0 2}$ \\
\hline Getxo & 0,00 & 0,00 \\
Oñate & 4,800 & 5,40 \\
Arrasate & 0,00 & 6,00 \\
Durango & 2,70 & 4,20 \\
Gorliz & 1,80 & 3,60
\end{tabular}

\section{6) La programación}

La programación en las emisoras municipales no se realiza de manera conjunta, sino más bien cada una de ellas lo resuelve de manera independiente y 
en la mayoría de los casos recurren a emitir solo por espacio de unas horas una programación propia y el resto del tiempo conectan con la radio autonómica unas, mientras que otras emiten música grabada. Así destaca:

1) Programación ajena, que recurren a ella ante la imposibilidad de poder cubrir de manera independiente las 24 horas al día. De modo que emite unos contenidos de elaboración propia durante algunas horas al día y el resto del tiempo optan por conectar con la Radio Autonómica como Getxo Irratia y Oñate Irratia

\section{Cuadro n.9. Programación}

\begin{tabular}{lrc}
$\mathbf{1 9 9 8}$ & Propia & Ajena \\
\hline Getxo & 33,34 & 66,66 \\
Oñate & 12,50 & 87,50 \\
Arrasate & 20,83 & 79,17
\end{tabular}

\section{Cuadro n.10. Programación}

\begin{tabular}{lrr}
$\mathbf{2 0 0 2}$ & Propia & Ajena \\
\hline Getxo & 29,60 & 70,40 \\
Oñate & 10,00 & 90,00 \\
Arrasate & 25,00 & 75,00 \\
Durango & 100,00 & 0,00 \\
Gorliz & 100,00 & 0,00
\end{tabular}

2) Elaboración propia durante las 24 horas al día, aunque gran parte de sus contenidos son musicales ${ }^{12}$. Su programación la integran:

1) Los informativos, donde dedican especial atención a los contenidos de ámbito local con porcentajes que oscilan entre el $32 \%$ en Getxo Irratia y el $13 \%$ en Gorliz. En ello se abordan los acontecimientos locales, deportivos, culturales y festivos de sus zonas de cobertura.

2) El entretenimiento supuso casi la mitad de los contenidos. En ellos se ofrece todo lo relativo a actos culturales, jornadas, conferencias, fiestas populares, además de temas de interés histórico de las localidades y deportes, así como los personajes más relevantes que constituyen interés.

12 La informatización de las redacciones ha permitido emitir durante las 24 horas al día. 
Los porcentajes variaban en 1998 desde el $58 \%$ en Arrasate Irratia hasta más del $40 \%$ en Oñate y Getxo Irratia. No obstante, desciende algo en el 2002, que es inferior al $38 \%$ con excepción de Arrasate Irratia que alcanza el $63 \%$.

3) La música también es un referente importante con porcentajes que oscilan entre el $16 \%$ en Arrasate hasta el $50 \%$ en Gorliz Irratia.

3) El idioma que se ha planteado como uno de los objetivos prioritarios en todas las emisoras encuentra grandes dificultades y solo Arrasate Irratia y Oñate Irratia emiten íntegramente en euskera, mientras que el resto de emisoras intentan alcanzar el $50 \%$ de la programación.

\section{Cuadro n.11. Programación propia 1998}

\begin{tabular}{lrrrr} 
& Inf General & Inf.local & Música & Magazines \\
\hline Getxo & 37,50 & 25,00 & 37,50 & 0,00 \\
Oñate & 0,00 & 8,33 & 33,33 & 58,34 \\
Arrasate & 0,00 & 15,00 & 42,50 & 42,50
\end{tabular}

Cuadro n.12. Programación propia 2002

\begin{tabular}{lrrrr} 
& Inf General & Inf.local & Música & Magazines \\
\hline Getxo & 37,50 & 32,00 & 30,50 & 0,00 \\
Oñate & 0,00 & 24,00 & 38,00 & 38,00 \\
Arrasate & 0,00 & 20,66 & 16,66 & 62,68 \\
Durango & 13,34 & 20,00 & 48,00 & 18,66 \\
Gorliz & 0,00 & 12,76 & 50,56 & 36,68
\end{tabular}

En la programación de las emisoras municipales se han producido algunas variaciones entre las que destacan:

1) Un incremento generalizado de las horas de emisión, llegando a emitir durante las 24 horas en la mayoría de los casos.

2) Mayor presencia de la radio en los acontecimientos locales.

3) Elaboración de informativos propios con periodicidad diaria, oscilando entre el $12,76 \%$ en Gorliz y el $32 \%$ en Getxo.

4) Incorporación de nuevas tecnologías en la emisora, hecho que facilita emitir mas tiempo de manera independiente. 
5) Disminución de las conexiones con la radio autonómica para los espacios informativos.

6) Se incrementa el número de trabajadores fijos en la mayoría de las emisoras.

7) Mayor continuidad de los espacios que se emiten.

\section{Legislación Municipal}

La Ley de Ordenación de las Telecomunicaciones de 18 de diciembre 1987 establecía las diferentes modalidades de los servicios de Radiodifusión Sonora en las distintas gamas de frecuencias, así como los requisitos para acceder a su prestación, aunque supeditaba la implantación de estos servicios públicos a los Planes Técnicos Nacionales que aprobaba el Gobierno y que elaboraba el Ministerio de Transportes, Turismo y Comunicaciones para todo el territorio nacional. No obstante, un Real Decreto anterior (27 de octubre 1978) establecía el Plan Técnico Nacional de Radiodifusión Sonora, pero a éste le seguía otro Real Decreto (8 de junio 1979), mediante el cual se disponía la reserva de las frecuencias necesarias para conseguir la cobertura prevista por las Sociedades Radio Nacional de España y Radio Cadena.

El Plan, que surgía de la Conferencia de Ginebra (1984) contemplaba la banda de Frecuencia Modulada desde el 87,5 MHz hasta $108 \mathrm{MHz}$, ante la necesidad de disponer de los medios necesarios para que las Comunidades Autónomas pudieran gestionar directamente el servicio de Radiodifusión Sonora en esta banda de frecuencias. Pero además existe el reconocimiento de la Ley de Ordenación de las Comunicaciones (18 de diciembre 1987), mediante la cual las Corporaciones locales tienen derecho a gestionar indirectamente, mediante concesión administrativa el servicio de radiodifusión. Asimismo, se aprobaba el Plan Técnico Nacional de Radiodifusión Sonora en Ondas Métricas con Modulación de Frecuencia (Real Decreto 10 de febrero 1989). En este Decreto (Art.5.a) se contemplaban las características técnicas de las emisoras correspondientes a las Corporaciones locales para la presentación del Servicio de Radiodifusión Sonora en Ondas Métricas con Modulación de Frecuencia que se ajustaran a los siguientes criterios:

1) Distribución de potencia radiada de las emisoras en $500 \mathrm{~W}, 150 \mathrm{~W}$ y 50 W respectivamente, según los municipios tengan más de 50.000 habitantes, entre 10.000 y 50.000 y menos de 10.000 habitantes.

2) La ubicación de la emisora dentro del caso urbano de la población a la que pertenezca (Art.5.d).

3) $\mathrm{Su}$ frecuencia debe de estar comprendida entre 107,0 y $107,9 \mathrm{MHz}$, siempre que no dificulte las comunicaciones de aeropuertos $\mathrm{u}$ otros servicios de interés. 
La Ley (18 de diciembre de 1987) también considera la gestión indirecta por las Corporaciones locales ${ }^{13}$ que requerirá la previa concesión del Gobierno o en su caso del órgano de la Comunidad Autónoma competente en materia de medios de comunicación social (Art.5.2). También prevé la posibilidad de adjudicación de concesiones de emisoras que reúnan las características distintas al caso anterior, pero que se solicitaban a través el órgano competente para otorgar la concesión (Art.5.4).

Asimismo, en disposición transitoria las emisoras correspondientes a las Corporaciones locales deben de someterse en cuanto a su organización, control parlamentario y garantías de acceso a dicho medio de los grupos sociales (Art.5.3) ${ }^{14}$. Esta Ley tiene como finalidad evitar la distorsión que se puede producir en el transcurso de las campañas electorales especialmente en las de carácter autonómico y municipal al producirse multitud de mensajes publicitarios en muchas emisoras de carácter local. Ante esta situación la aplicación de criterios de proporcionalidad en el reparto de espacios gratuitos de propaganda electoral que regula la inserción gratuita de estos espacios y se reserva únicamente para campañas de ámbito municipal, que en su único artículo establece ${ }^{15}$ :

No pueden contratarse espacios de publicidad electoral en las emisoras de radiodifusión sonora de titularidad municipal.

La Ley no contempla el uso de espacios gratuitos cuando se trata de comicios diferentes a los municipales (Art.1.3), pero si prevé el derecho a utilizar las emisoras de titularidad pública los partidos, federaciones, coaliciones, agrupaciones que concurran a las elecciones municipales, y resalta de manera específica:

El respeto al pluralismo y a los valores de igualdad en los programas difundidos durante los periodos electorales por las emisoras de radiodifusión sonora de titularidad municipal.

Una nueva Ley (8 de abril 1991), para la regulación y el tratamiento publicitario electoral en un medio de comunicación social y por tanto de titularidad pública como son las emisoras municipales, así como para la organización y control de las emisoras municipales que tiene su justificación en:

13 La Ley de 18 de diciembre de 1987, también, estima que la Dirección General de Telecomunicaciones determinará el valor de la frecuencia y las características técnicas a las que deba de ajustarse (Art.5.3).

14 La aplicación del presente Real Decreto quedará en suspenso hasta tanto entre en vigor la citada ley.

15 Ley Orgánica del Régimen Electoral general (19 de junio de 1985). 
La necesidad de facilitar la prestación de tal servicio por medio de emisoras de radiodifusión sonora de titularidad municipal, aconseja establecer un marco jurídico adecuado, con el fin de que los ayuntamientos sean las gestoras del mismo.

Después de la promulgación de la Ley (18 de diciembre 1987) de Ordenación de las Telecomunicaciones por primera vez adquiere rango de ley la ordenación jurídica de la radiodifusión sonora en España y se contempla la figura de la concesión administrativa para la prestación de este servicio público por las Corporaciones locales. Asimismo, procede a dotar a las mismas del amparo legal necesario en cumplimiento de lo dispuesto en la Constitución (Art. 20.3) respecto de los medios de comunicación social de titularidad pública ${ }^{16}$. De esta manera se sientan los criterios básicos establecidos en otros textos legales en aspectos tales como organización y control de medios de comunicación públicos existentes, como es el caso del Estatuto de Radio y Televisión, así como todas aquellas reguladoras de los Entes públicos de Radiodifusión y Televisión creados en diversas comunidades Autónomas ${ }^{17}$.

En cuanto a la gestión económica, la Ley no impone nada, se remite a las propias instituciones municipales que podrán decidir aquello que consideren más adecuado a sus necesidades. De modo, que el Pleno Municipal será el órgano que realizará el control de la emisora de radio. Así se pretende dotar a la comunidad de medios de comunicación de carácter local que ofrezcan una información plural que garantice una diversidad informativa como reconoce la propia Constitución:

1) La objetividad, veracidad e imparcialidad de las informaciones.

2) La separación entre informaciones e imparcialidad de las informaciones de quienes sustentan estas últimas y su libre expresión, con los límites de la Constitución (Art. 20.4).

3) El respeto al pluralismo político, religioso, social, cultural y lingüístico.

4) El respeto al honor, a la intimidad de las personas, a la propia imagen y demás derechos y libertades reconocidas en la Constitución y la protección de la juventud y de la infancia.

La legislación considera que tienen que ser necesariamente gestionadas por medio de alguna de las formas previstas (Art 3.1) en las Bases de Régimen Local ${ }^{18}$. Además, para su financiación prevé que tiene que ser conforme a lo establecido en la Ley (28 de diciembre 1988) Reguladora de las Haciendas Locales y mediante ingresos comerciales propios. La Ley contempla que la programación

16 Ley de 18 de diciembre de 1987 referente a la Ordenación de las Telecomunicaciones.

17 Ley de 10 de enero de 1980, del Estatuto de Radio y Televisión.

18 Art 85.3 de la Ley de 2 de abril de 1985, reguladoras de las Bases de Régimen Local. 
puede ser propia o producido por otras emisoras también, municipales (Art.2.3) aunque, en su último caso será el Pleno del Ayuntamiento quien ejerza el control final del servicio público de Radiodifusión Sonora en Ondas Métricos con Modulación de Frecuencia.

Unos años más tarde se regula el otorgamiento de concesión y la asignación de frecuencias para la explotación del servicio público de Radiodifusión Sonora en Ondas Métricos con Modulación de Frecuencia por las Corporaciones locales, tiene para aquellos casos donde la competencia concesional corresponda al Estado de la nación y no a las autonomías (Real Decreto 23 de octubre 1992). En este caso el Gobierno les exige la certificación del acta del pleno de la Corporación Municipal donde se haya acordado la concesión administrativa, junto con la acreditación del censo. En cuanto a las características de la emisora también deben de presentar el plano de la situación donde se tiene previsto instalar el emisor, junto con las coordenadas geográficas y la memoria explicativa de la programación que se intente desarrollar. Las concesiones serán por un periodo de tiempo de 10 años, que pueden ser prorrogados antes de su expiración por periodos iguales y sucesivos mediante solicitud del concesionario.

Finalmente otro Real Decreto (5 septiembre 1997) contempla un incremento de frecuencias para la gestión indirecta de emisoras, dentro del Plan Técnico Nacional de Radiodifusión Sonora en Ondas Métricos con Modulación de Frecuencia. El Decreto aprueba la incorporación del Plan Técnico Nacional de Radiodifusión Sonora en Ondas Métricas con Modulación de Frecuencia de una nueva relación de frecuencias que se pueden utilizar por gestión indirecta (Art.1).

\section{Decreto autonómico}

La Comunidad Autónoma tiene las competencias en cuanto se refiere al desarrollo legislativo en materia de medios de comunicación social, y por ello, como sucedió con anterioridad en el caso de las emisoras comerciales, desarrolla su propia legislación para dotar a las Corporaciones locales que quieran de un servicio de Radiodifusión Sonora en Ondas Métricas con Modulación de Frecuencia ${ }^{19}$.

Mediante un nuevo Decreto (22 de marzo 1994) se pretende regular el régimen de otorgamiento de concesiones del Servicio Público de Radiodifusión Sonora a las entidades Municipales de la Comunidad Autónoma del País Vasco, cuya competencia corresponde al Ente autónomo. También, tiene en cuenta las características a las que se deben de someter las emisoras municipales, como en casos anteriores resalta de manera prioritaria (Art.2.2.1).

19 En virtud de su Art. 19 del Estatuto de Autonomía. 
La protección y fomento de la singularidad cultural y lingüística del Pueblo Vasco $y$ de cuantos otros elementos de tal orden constituyan la idiosincrasia local.

Indudablemente, tiene como finalidad preservar el interés público, por los concesionarios donde se especifica que:

Se asegurara una presencia del euskera al menos, proporcional a la suma de los porcentajes que puedan extraerse para cada municipio del ultimo Anuario Estadístico Vasco, publicado por el EUSTAT, cada año.

Asimismo, el euskera se contemplará con las medidas de euskaldunización y alfabetización de la población, las cuales se desarrollan preferentemente en el Euskaltegi Municipal homologado.

En cuanto a las características técnicas el Decreto autonómico (Art.2.2.2 b), no introduce ninguna variación con respecto al Real Decreto (23 de octubre 1992) y en el Plan Técnico de Radiodifusión Sonora en Ondas Métricas con Modulación de Frecuencia ${ }^{20}$. Como en el caso anterior clasifica las emisoras en tres tipos según el número de habitantes del municipio donde se pretenda instalar la emisora

El tipo A para municipios con población superior a 50.000 habitantes, del tipo B a municipios con población entre 10.000 y 50.000 habitantes, y del tipo C, a municipios con población inferior a 10.000 habitantes.

En la ubicación de las frecuencias tampoco existen discrepancias (Art.2. 2.2 e).

La banda 107.0 a $107.9 \mathrm{MHz}$, salvo que dificultades técnicas derivadas de la proximidad de aeropuertos o interferencias a otros servicios de radiocomunicaciones impidan su planificación en dicha banda.

El procedimiento para su solicitud (Art.3) establece las mismas condiciones como son la solicitud por el Alcalde-Presidente de la Corporación Municipal (Art.3.a); Certificación del acuerdo de la Corporación Municipal (Art.3.b); Certificación acreditativa de la población censada (Art.3.c); Plano de situación prevista del centro emisor, con indicación de su cota y coordenadas geográficas (Art.3.d); Memoria, que recoja las características técnicas del equipo e instalaciones para prestar servicio (Art.3.e). En cuanto se refiere a la dotación de personal, el Decreto

20 Real Decreto de 23 de octubre de 1992 y en el Plan Técnico de Radiodifusión Sonora en Ondas Métricas con Modulación de Frecuencia. 
Señala la dotación de personal que se prevea vaya a prestar el servicio, y su vínculo con la entidad municipal, así como los servicios externos que se prevean contratar.

Una vez notificada la reserva de frecuencia la Corporación Municipal dispondrá de un plazo de tres meses para comunicar al Departamento de Cultura las características concretas del servicio (Art.4.2). Si el proyecto resulta aprobado, la Corporación Municipal obtendrá la concesión por un periodo de diez años (Art.6.1), con posibilidad de renovarlos por un periodo de tiempo igual. Para la financiación de la emisora el Decreto Autonómico tampoco hace diferencias:

Además de lo que establezca la normativa aplicable sobre Haciendas Locales que sea aplicable a cada Entidad Municipal; las emisoras Municipales de conformidad a aquella podrán obtener ingresos comerciales propios (Art.7).

El Decreto también establece algunas obligaciones (Art.8) que no podrán eludir, como son la obligatoriedad de difundir íntegra y gratuitamente los comunicados y avisos de carácter oficial y de interés público que le sean remitidos por el Gobierno Vasco, u otras autoridades que reglamentariamente se determinen (Art.8.b).

En cuanto a la publicidad electoral en emisoras municipales tendrán que velar por el estricto cumplimiento de la normativa vigente (Art.8.c).

\section{FUENTES}

\section{1) Bibliografía:}

- BASSET, Luis: De las ondas rojas a las radios libres. Gustavo Gili. Barcelona, 1981.

- DÍAZ Mancisidor y URRUTIA, Víctor: La nueva radio. U.P.V. Bilbao, 1986

- SANTOS DÍEZ, M. Teresa: La radio vasca. (1978-1998). UPV. Bilbao, 1999.

\section{2) Fuentes Oficiales:}

- B.O.E.

- B.O.P.V

- Gobierno vasco

- Ayuntamientos

\section{3) Entrevistas personales con los responsables de las emisoras}

